The Improved Comparative Reactivity Method (ICRM): measurements of $\mathrm{OH}$ reactivity at high-NO $\mathrm{X}_{\mathrm{x}}$ conditions in \title{
ambient air
}

Wenjie Wang ${ }^{1,3 \#}$, Jipeng Qi ${ }^{1,2 \#}$, Jun Zhou ${ }^{1,2}$, Bin Yuan ${ }^{1,2^{*}}$, Yuwen Peng ${ }^{1,2}$, Sihang Wang $^{1,2}$ Jonathan Williams $^{4}$, Vinayak Sinha ${ }^{5}$, Min Shao ${ }^{1,2}$

${ }^{1}$ Institute for Environmental and Climate Research, Jinan University, Guangzhou 511443, China.

${ }^{2}$ Guangdong-Hongkong-Macau Joint Laboratory of Collaborative Innovation for Environmental Quality, Guangzhou 511443, China.

${ }^{3}$ Multiphase Chemistry Department, Max Planck Institute for Chemistry, Mainz 55128, Germany.

${ }^{4}$ Atmospheric Chemistry Department, Max Planck Institute for Chemistry, Mainz 55128, Germany.

${ }^{5}$ Department of Earth and Environmental Sciences, Indian Institute of Science Education and Research (IISER), Mohali 140306, India.

\#W.J.W. and J.P.Q. contributed equally to this work.

*Correspondence to: byuan@jnu.edu.cn 


\section{Calculation of $X_{R}$}

Due to the variation of reagent ion source and sample humidity, the pyrrole $\left(\mathrm{C}_{4} \mathrm{H}_{5} \mathrm{~N}\right)$ ion signal is normalized to a standard reagent ion signal of $10^{6}$ counts/s $(\mathrm{cps})$ as following in Eq. 1.

$$
\text { Pyrrole }_{n c p s}=\frac{i\left[\mathrm{C}_{4} \mathrm{H}_{5} \mathrm{NH}^{+}\right] \times 10^{6}}{i\left[\mathrm{H}_{3} \mathrm{O}^{+}\right]+\mathrm{X}_{R} \times i\left[\mathrm{H}_{3} \mathrm{O}^{+} \mathrm{H}_{2} \mathrm{O}\right]}
$$

Where Pyrrole $_{n c p s}$ is a normalized signal of the pyrrole, and $i\left[\mathrm{C}_{4} \mathrm{H}_{5} \mathrm{NH}^{+}\right]$, $i\left[\mathrm{H}_{3} \mathrm{O}^{+}\right]$, and $i\left[\mathrm{H}_{3} \mathrm{O}^{+} \mathrm{H}_{2} \mathrm{O}\right]$ represent the signals of different product ions, respectively. The value of $X_{R}$ not only represents difference in detection efficiencies of detector, but also the difference in rate coefficients of the proton transfer reactions $\mathrm{H}_{3} \mathrm{O}^{+}+$pyrrole and $\mathrm{H}_{3} \mathrm{O}^{+}\left(\mathrm{H}_{2} \mathrm{O}\right)+$ pyrrole (de Gouw et al., 2003; de Gouw et al., 2007).

Here, the $\mathrm{X}_{\mathrm{R}}$ value of pyrrole was determined by the laboratory experiment. The $i\left[\mathrm{C}_{4} \mathrm{H}_{5} \mathrm{NH}^{+}\right], i\left[\mathrm{H}_{3} \mathrm{O}^{+}\right]$, and $i\left[\mathrm{H}_{3} \mathrm{O}^{+} \mathrm{H}_{2} \mathrm{O}\right]$ were measured from a dry $(0 \%)$ to $100 \%$ humidified pyrrole standard gas, respectively. The pyrrole signal become independent of relative humidity when normalized to $i\left[\mathrm{H}_{3} \mathrm{O}^{+}\right]+\mathrm{X}_{\mathrm{R}} \times i\left[\mathrm{H}_{3} \mathrm{O}^{+} \mathrm{H}_{2} \mathrm{O}\right]$. In other words, the correlation coefficient $\left(\mathrm{r}^{2}\right)$ of relative humidity and normalized pyrrole signal reaches a minimum at the optimized $X_{R}$ value. This method is inspired by the calculation of enhancement ratios and the source contribution of different species in the previous studies (Millet et al., 2005; Yuan et al., 2010). Figure S1 (a) shows the result of the correlation coefficient of at different $X_{R}$ with a bin of 0.01 values. We found that $r^{2}$ is the smallest when the $X_{R}$ value is 0 . Figure $S 1$ (b) shows the time series of pyrrole signals before and after normalizing to $i\left[\mathrm{H}_{3} \mathrm{O}^{+}\right]+\mathrm{X}_{\mathrm{R}} \times i\left[\mathrm{H}_{3} \mathrm{O}^{+} \mathrm{H}_{2} \mathrm{O}\right]$, respectively. It is shown that pyrrole signal reaches a stable level after normalized with the increase of relative humidity. Therefore, the $\mathrm{X}_{\mathrm{R}}$ value is determined as 0 . 
Table S1. The list of all species used to calculate $\mathrm{OH}$ reactivity in this study.

\begin{tabular}{|c|c|c|}
\hline Species name & Species name & Species name \\
\hline Alkanes & n-Undecane & 1,2,3-Trimethylbenzene \\
\hline Ethane & n-Dodecane & p-Diethylbenezen \\
\hline Propane & Alkenes & m-Diethylbenezen \\
\hline iso-Butane & Ethene & Alkyne \\
\hline n-Butane & Propene & Acetylene \\
\hline iso-Pentane & cis-2-Butene & OVOCs \\
\hline n-Pentane & trans-2-Butene & Formaldehyde \\
\hline Cyclopentane & 1-Butene & Methanol \\
\hline 2-Methylpentane & 1-Pentene & Acetaldehyde \\
\hline n-Hexane & Isoprene & Ethanol \\
\hline Cyclohexane & cis-2-Pentene & Acrolein \\
\hline 2,2-Dimethylbutane & trans-2-Pentene & Acetone \\
\hline 2,3-Dimethylbutane & 1-Hexene & Propanol \\
\hline 3-Methylpentane & Aromatics & Furan \\
\hline 3-Methylhexane & Benzene & $\mathrm{MVK}+\mathrm{MACR}$ \\
\hline 2,2,4-Trimethylpentane & Toluene & MEK \\
\hline Methylcyclopentane & Ethylbenzene & Pentanones \\
\hline n-Heptane & $\mathrm{x}, \mathrm{p}$-Xylene & Phenol \\
\hline Methylcyclohexane & Styrene & 2-Furaldehyde \\
\hline 2,3,4-Trimethylpentane & o-Xylene & Benzyl alcohol \\
\hline 2-Methylheptane & n-Propylbenzene & Inorganics \\
\hline 3-Methylheptane & isopropylbenzene & $\mathrm{CO}$ \\
\hline 2,4-Dimethylpentane & o-Ethyltoluene & NO \\
\hline 2,3-Dimethylpentane & m-Ethyltoluene & $\mathrm{NO}_{2}$ \\
\hline 2-Methylhexane & p-Ethyltoluene & $\mathrm{SO}_{2}$ \\
\hline n-Octane & 1,2,4-Trimethylbenzene & $\mathrm{O}_{3}$ \\
\hline n-Decane & 1,3,5-Trimethylbenzene & \\
\hline
\end{tabular}



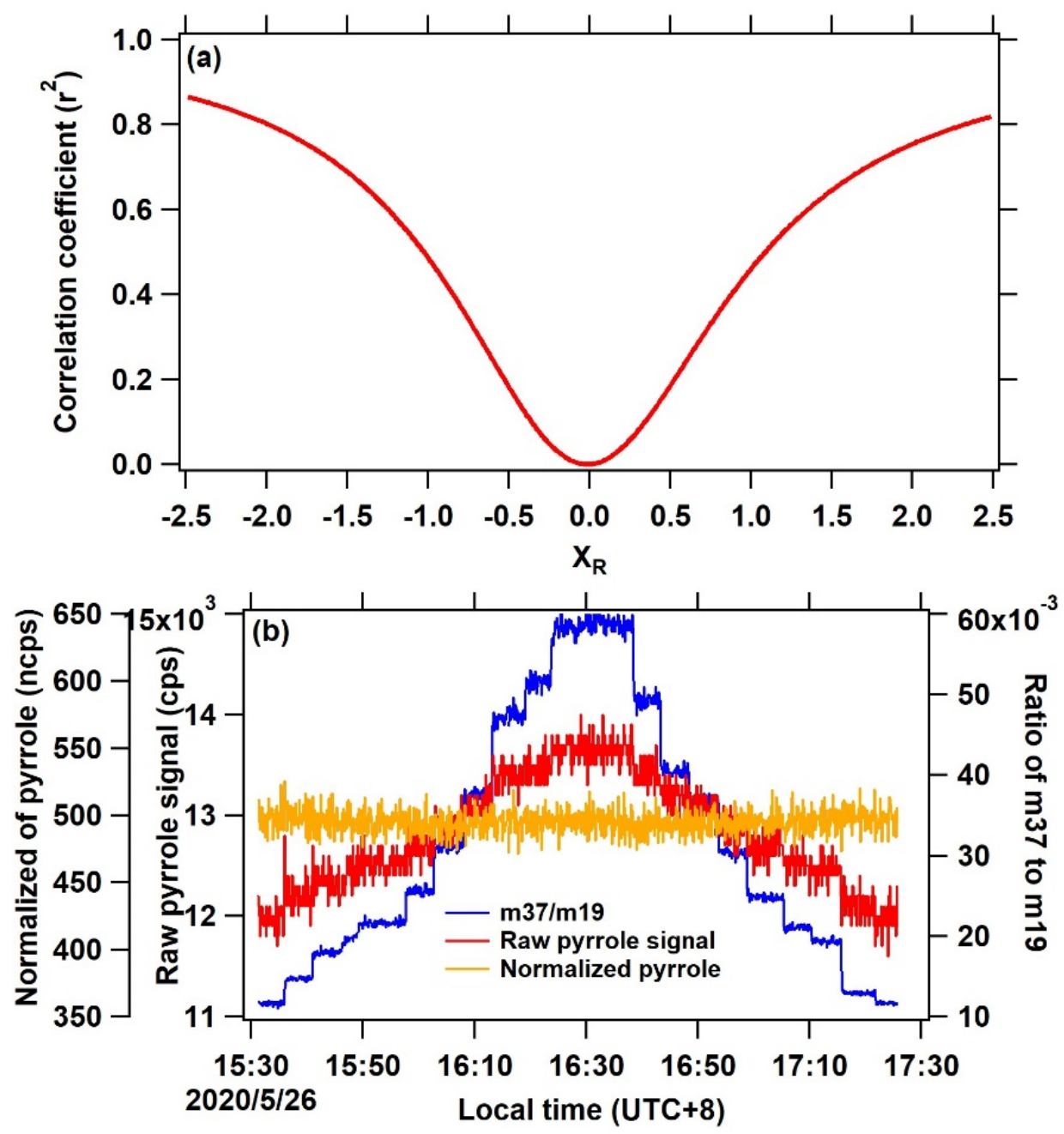

49 Figure S1. (a) The horizontal represents different $X_{R}$ values (from -2.5 to 2.5). The

50 vertical represents the correlation coefficient that pyrrole is normalized to $\mathrm{H}_{3} \mathrm{O}^{+}$signals

51 and $\mathrm{m} 37 / \mathrm{m} 19$ at different $\mathrm{X}_{\mathrm{R}}$ values. (b) The time series of the signal of pyrrole in cps

52 (red) and in ncps (yellow, normalized to m19 and m37) with the change of humidity

53 (blue, represented as the ratio of $\mathrm{m} 37$ to $\mathrm{m} 19$ ). 

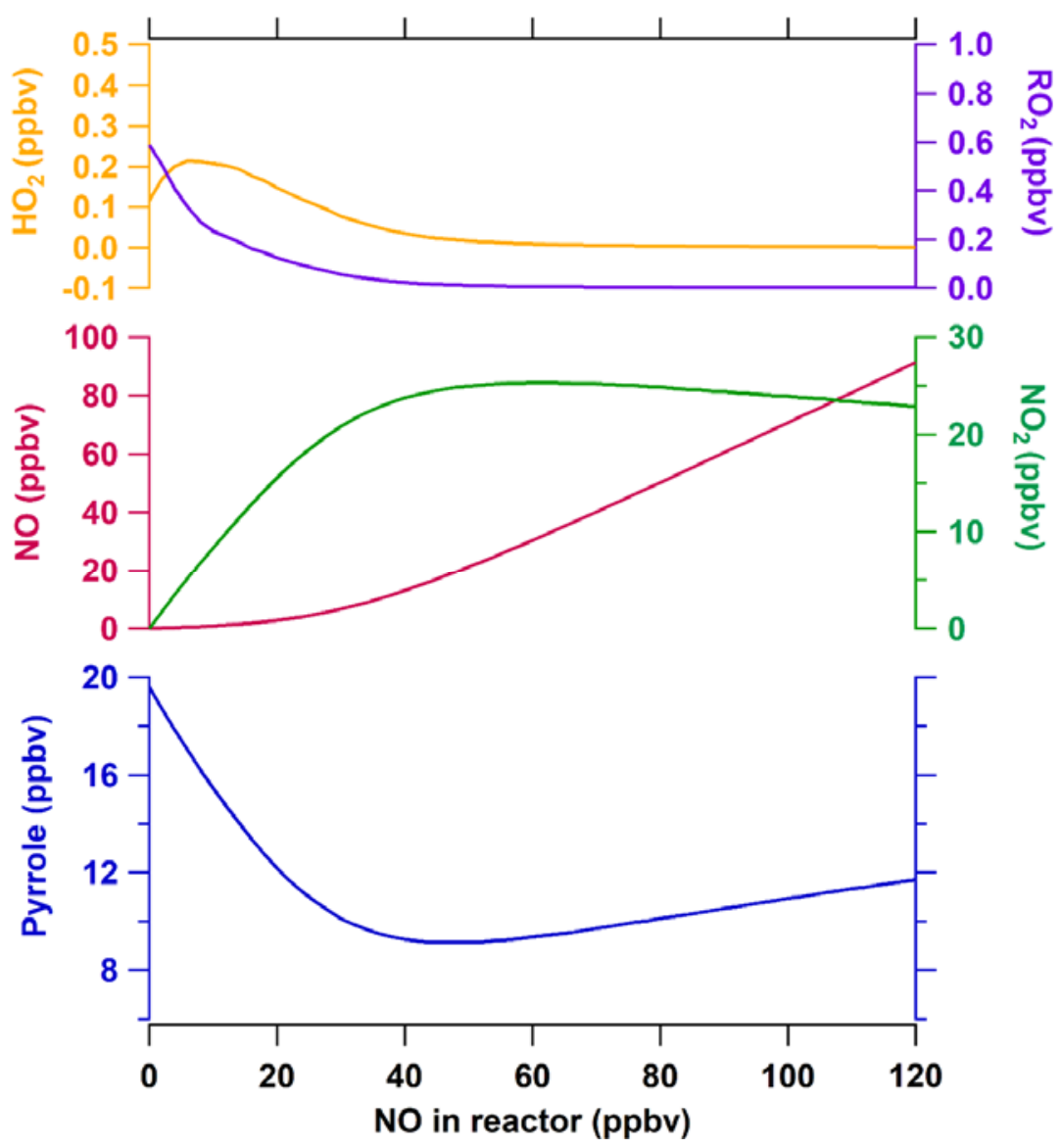

55 Figure S2. The remaining concentrations of pyrrole, $\mathrm{NO}, \mathrm{NO}_{2}, \mathrm{HO}_{2}$, and $\mathrm{RO}_{2}$ 56 outflowing of the reactor (with the reaction time of $\sim 11 \mathrm{~s}$ ) as a function of introduced $57 \quad \mathrm{NO}$ in the reactor. 

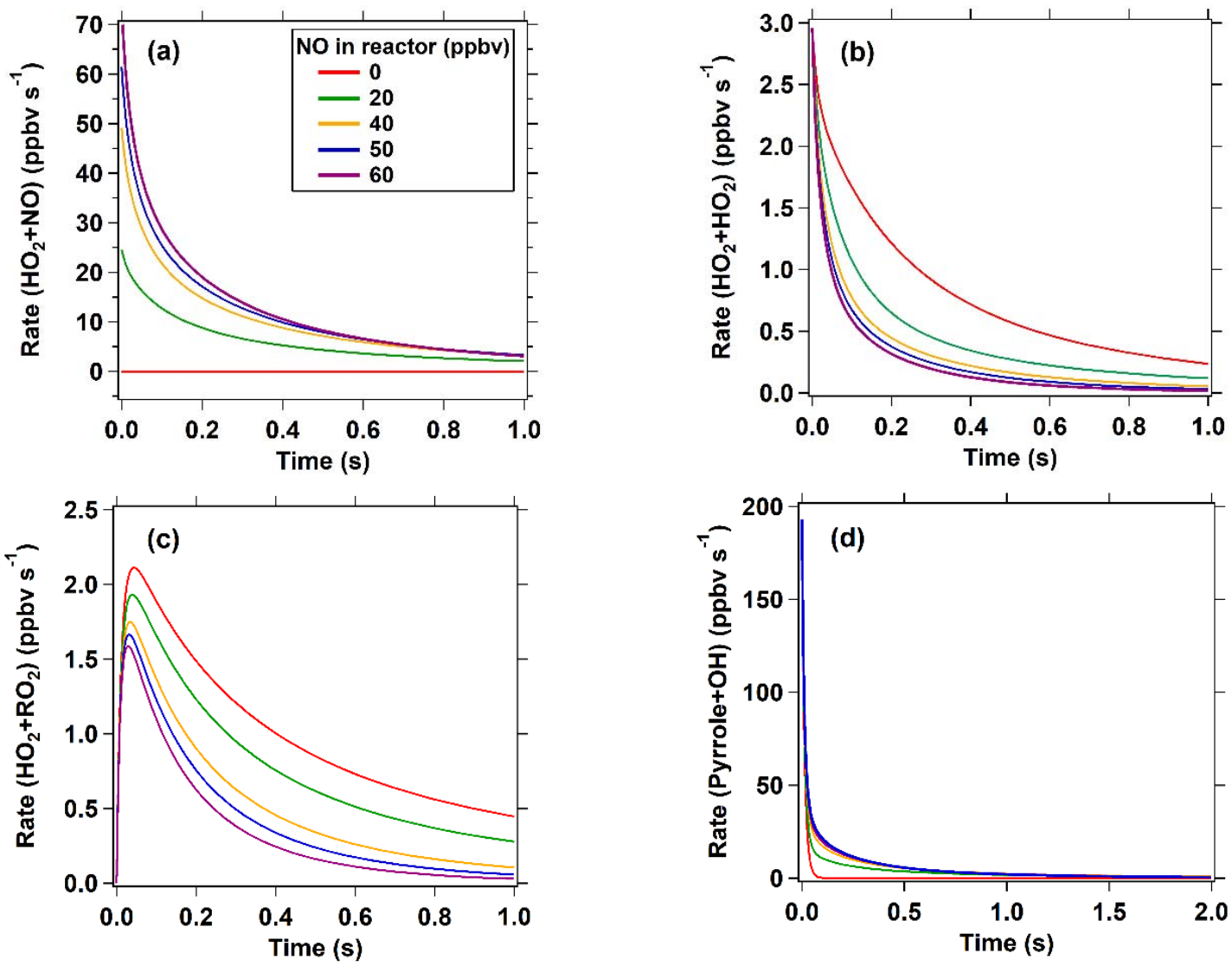

Figure S3. The reaction rates of $\mathrm{HO}_{2}+\mathrm{NO}, \mathrm{HO}_{2}+\mathrm{HO}_{2}, \mathrm{HO}_{2}+\mathrm{RO}_{2}$ and Pyrrole $+\mathrm{OH}$ as a

60 function of reaction time in the reactor. Four levels of introduced NO concentrations $(0$,

$6120,40,50,60 \mathrm{ppbv}$ ) was selected.The reaction time ranging from 0 to $1 \mathrm{~s}$ is displayed

62 due to the high reaction rates mainly occurred during this period. 

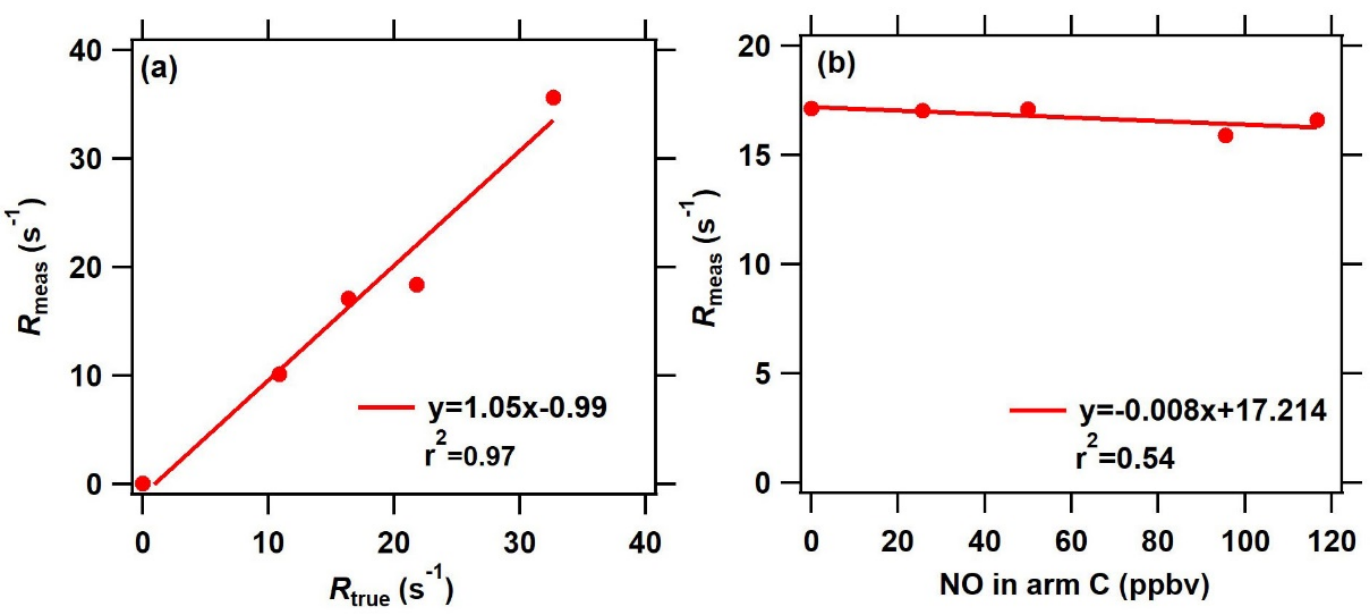

64

65 Figure S4. (a) The $\mathrm{OH}$ reactivity calibration of $\mathrm{NO}_{2}$, (b) Comparison of measured and

66 true $\mathrm{OH}$ reactivity of $\mathrm{NO}_{2}$ at different $\mathrm{NO}$ concentrations introduced through $\operatorname{arm} \mathrm{C}$ in

67 ICRM system.

68 

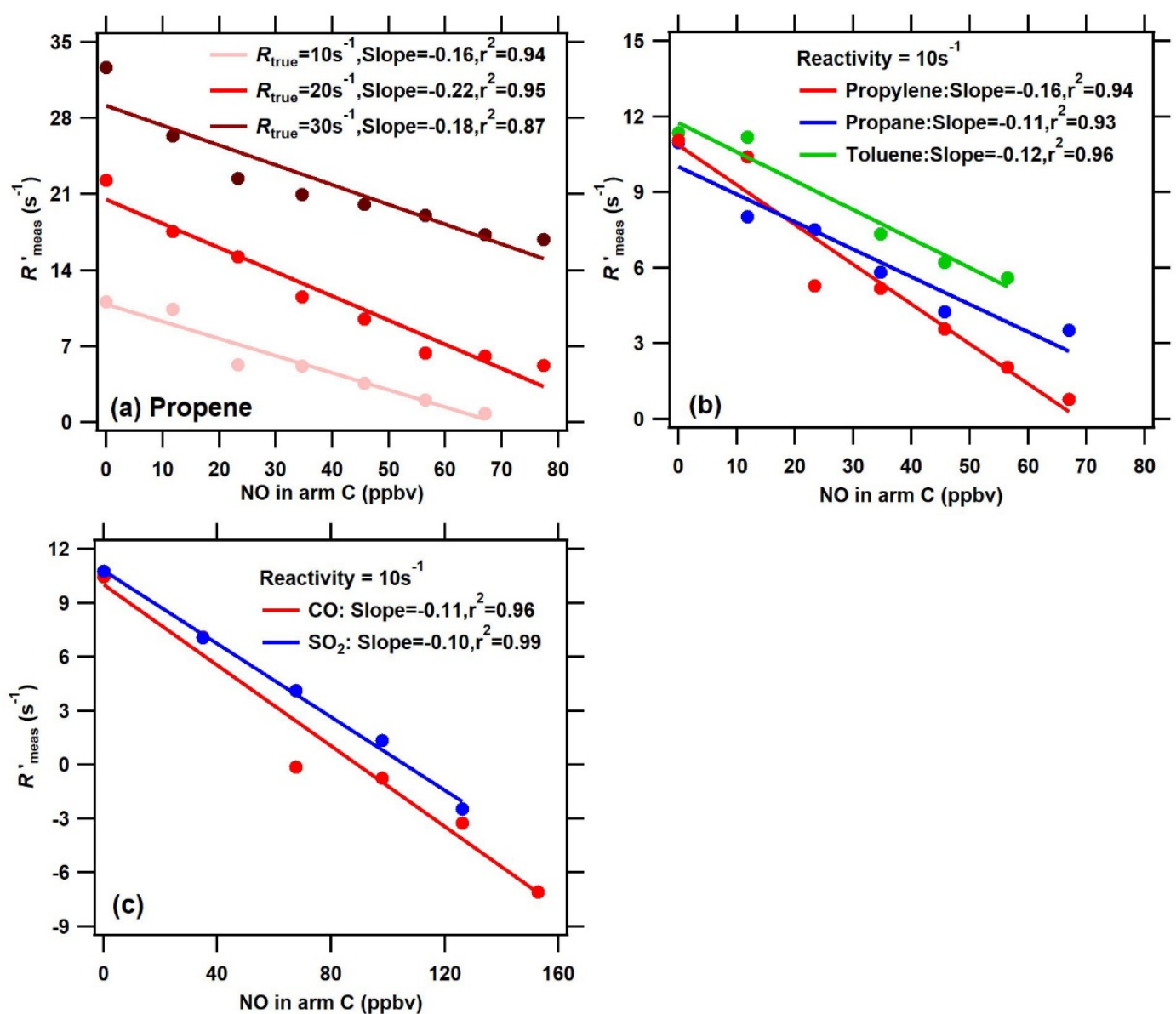

Figure S5. The corrected measured reactivity $\left(R^{\prime}\right.$ meas $)$ using the calibration factor $\alpha_{3}$

$71\left(R^{\prime}\right.$ meas $\left.=\left(\frac{1}{\alpha_{3}} * R_{\text {meas }}\right)\right)$ as a function of NO concentrations at (a) different levels of

72 VOCs reactivity for the same species (propene) and (b) different VOCs species for the

73 same $\mathrm{OH}$ reactivity level $\left(10 \mathrm{~s}^{-1}\right)$; (c) The response of the $R^{\prime}$ meas to NO concentrations

74 at different inorganic species for the same $\mathrm{OH}$ reactivity level $\left(10 \mathrm{~s}^{-1}\right)$. The $\mathrm{NO}, \mathrm{CO}$,

$75 \mathrm{SO}_{2}$, and VOCs were introduced into the reactor through arm $\mathrm{C}$. 


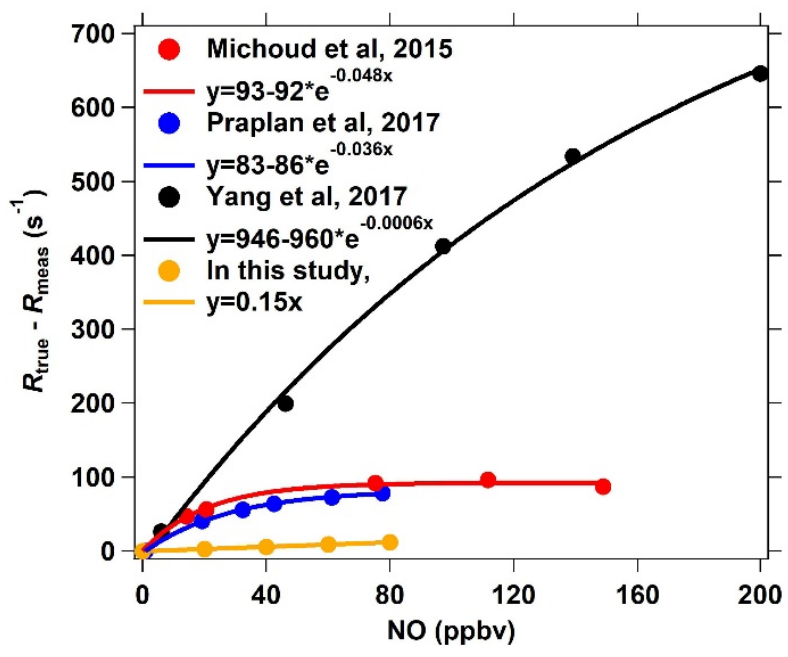

78 Figure S6. The effect of NO on the difference between true reactivity and measured $79 \mathrm{OH}$ reactivity ( $\left.R_{\text {true }}-R_{\text {meas }}\right)$ in the original CRM system. In this study, to correct the 80 systematic deviation at ambient $\mathrm{NO}=0$, the $R_{\text {true }}-R_{\text {meas }}$ is defined as the difference 81 between true $\mathrm{OH}$ reactivity $\left(R_{\text {true }}\right)$ and the corrected measured $\mathrm{OH}$ reactivity $\left(R^{\prime}\right.$ meas $)$ 82 using the calibration factor $\alpha_{1}\left(R^{\prime}\right.$ meas $\left.=\left(\frac{1}{\alpha_{1}} * R_{\text {meas }}\right)\right)$. 


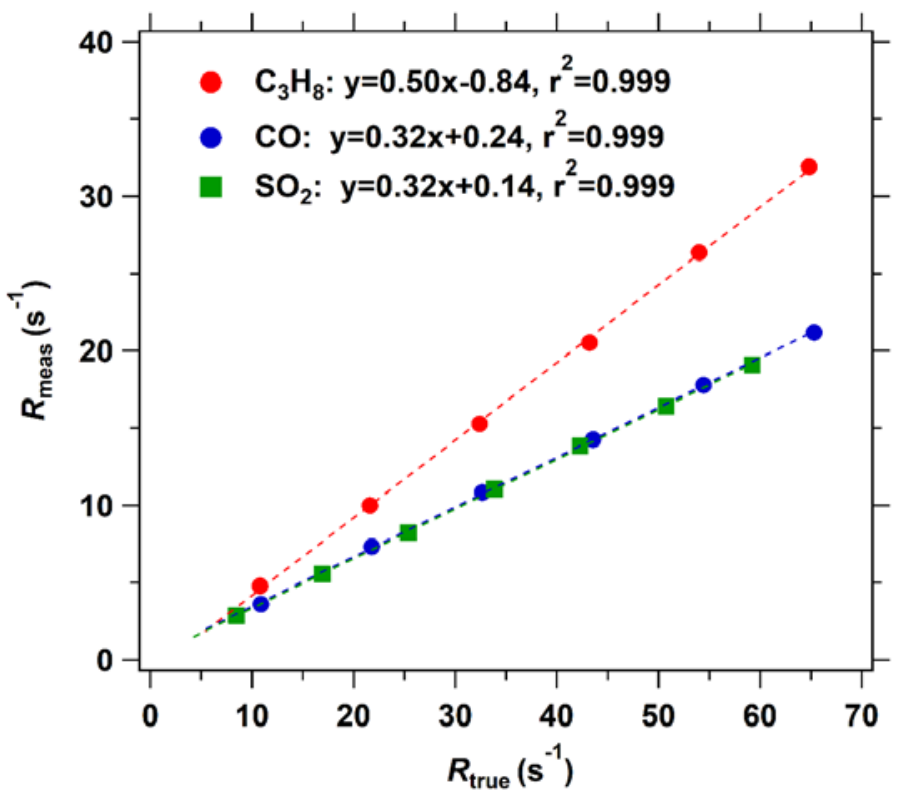

Figure S7. Linear correlation between measured and true $\mathrm{OH}$ reactivity of propane, $85 \mathrm{CO}$, and $\mathrm{SO}_{2}$ simulated by box-model. 


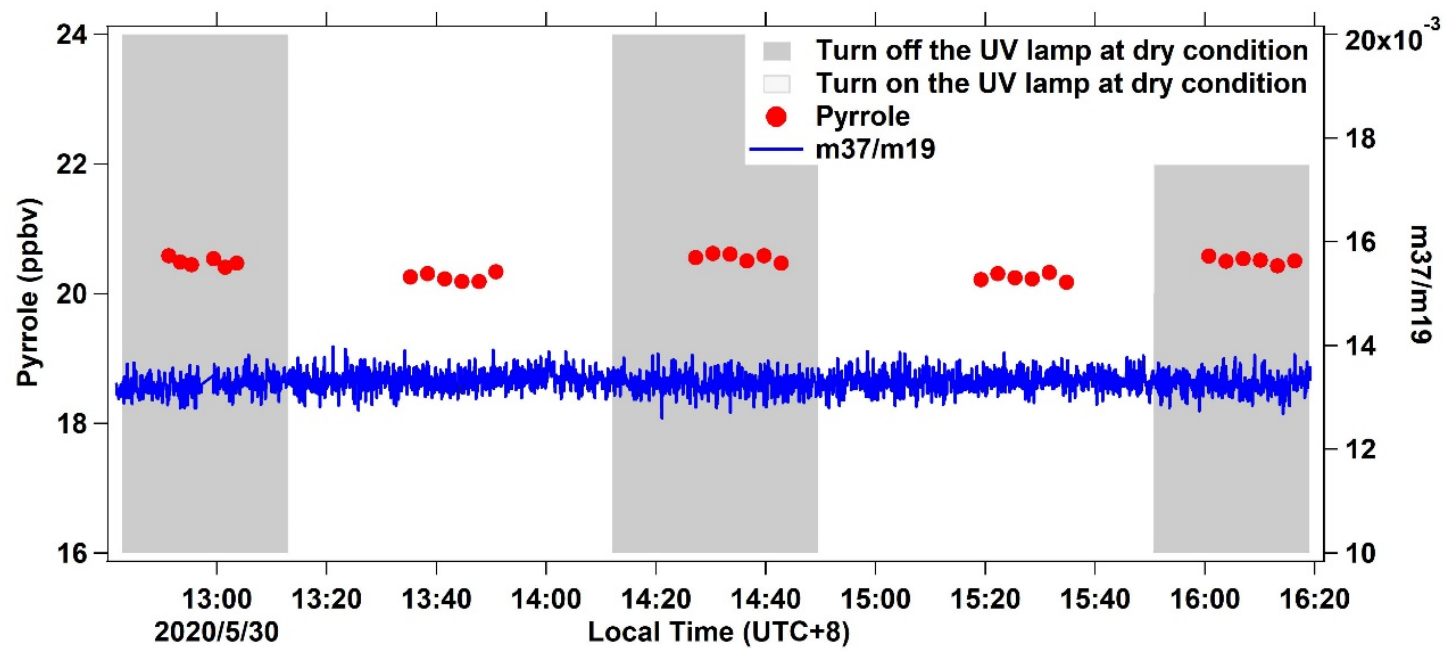

Figure S8. The variation in pyrrole concentration due to photolysis effect in the ICRM

88 system. Two modes were tested by turning on and off the mercury lamp at dry condition 89 (no humidification). 


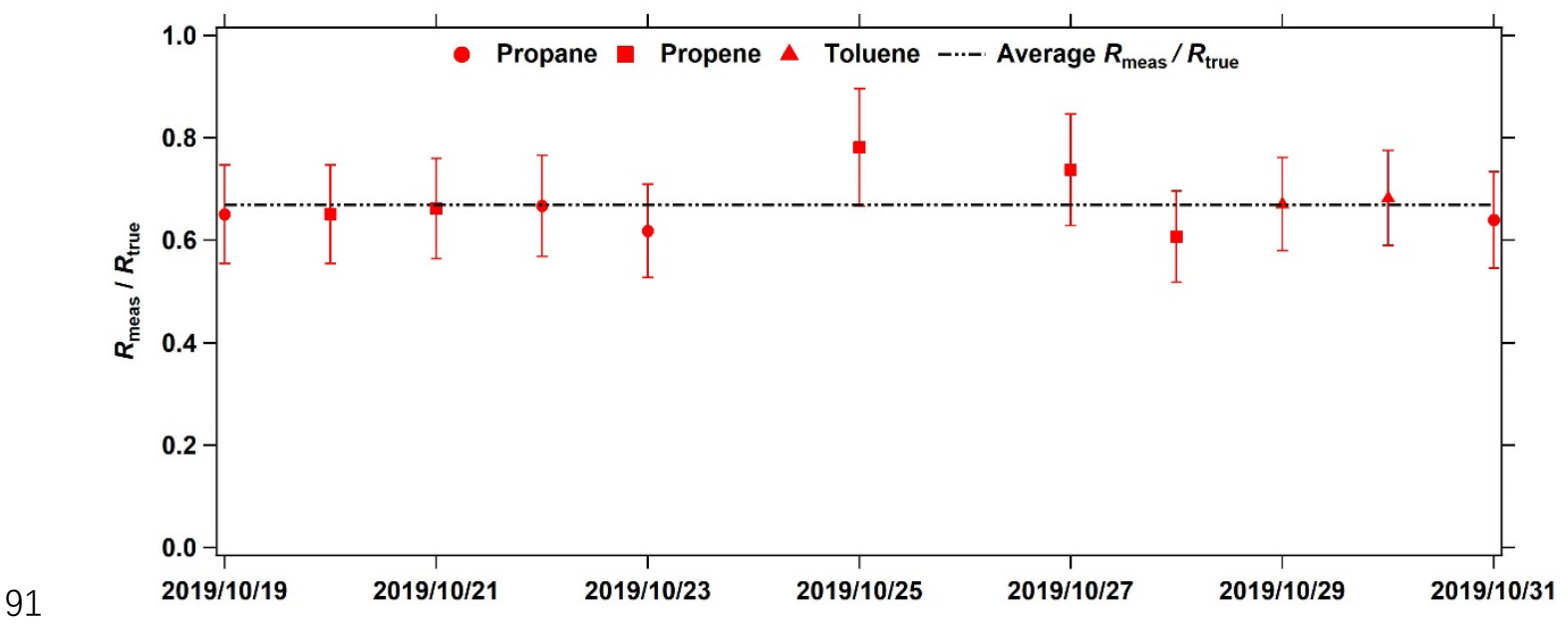

92 Figure S9. The daily calibration of measured reactivity during the field campaign at

93 Heshan site. The ratio of $R_{\text {meas }}$ to $R_{\text {true }}\left(R_{\text {meas }} / R_{\text {true }}\right)$ of each day is given. The dashed line 94 represents the average value of $R_{\text {meas }} / R_{\text {true }}$ during the measurement. Three VOC standard gases (propane, propene and Toluene) were used for the calibration. 


\section{References}

de Gouw, J. and Warneke, C.: Measurements of volatile organic compounds in the earth's atmosphere using proton-transfer-reaction mass spectrometry, Mass Spectrom Rev, 26, 223-257, 2007.

de Gouw, J. A., Goldan, P. D., Warneke, C., Kuster, W. C., Roberts, J. M., Marchewka, M., Bertman, S. B., Pszenny, A. A. P., and Keene, W. C.: Validation of proton transfer reaction-mass spectrometry (PTR-MS) measurements of gas-phase organic compounds in the atmosphere during the New England Air Quality Study (NEAQS) in 2002, Journal of Geophysical Research: Atmospheres, 108, 2003.

Millet, D. B. and Neil M. Donahue, S. N. P., Andrea Polidori, Charles O. Stanier, Barbara J. Turpin, Allen H. Goldstein: Atmospheric volatile organic compound measurements during the Pittsburgh Air Quality Study: Results, interpretation, and quantification of primary and secondary contributions, Journal of Geophysical Research, 110, 1-17, 2005.

Yuan, B., Liu, Y., Shao, M., Lu, S., and Streets, D. G.: Biomass Burning Contributions to Ambient VOCs Species at a Receptor Site in the Pearl River Delta (PRD), China, Environmental Science \& Technology, 44, 4577-4582, 2010. 